\title{
Stage IVA Hepatocellular Carcinoma AJCC v7
}

National Cancer Institute

\section{Source}

National Cancer Institute. Stage IVA Hepatocellular Carcinoma A/CC v7. NCI Thesaurus. Code C5764.

Stage IVA includes: Any T, N1, M0. N1: Regional lymph node metastasis. M0: No distant metastasis. (AJCC 7th ed.) 